ARTICLE

DOI: $10.1038 / s 41467-018-03123-0$

\title{
Oxidation-stable amine-containing adsorbents for carbon dioxide capture
}

\author{
Kyungmin Min ${ }^{1}$, Woosung Choi ${ }^{1}$, Chaehoon $\mathrm{Kim}^{1} \&$ Minkee Choi ${ }^{1}$
}

Amine-containing solids have been investigated as promising adsorbents for $\mathrm{CO}_{2}$ capture, but the low oxidative stability of amines has been the biggest hurdle for their practical applications. Here, we developed an extra-stable adsorbent by combining two strategies. First, poly(ethyleneimine) (PEI) was functionalized with 1,2-epoxybutane, which generates tethered 2-hydroxybutyl groups. Second, chelators were pre-supported onto a silica support to poison p.p.m.-level metal impurities (Fe and $\mathrm{Cu}$ ) that catalyse amine oxidation. The combination of these strategies led to remarkable synergy, and the resultant adsorbent showed a minor loss of $\mathrm{CO}_{2}$ working capacity (8.5\%) even after 30 days aging in $\mathrm{O}_{2}$ containing flue gas at $110{ }^{\circ} \mathrm{C}$. This corresponds to a $~ 50$ times slower deactivation rate than a conventional $\mathrm{PEI}$ /silica, which shows a complete loss of $\mathrm{CO}_{2}$ uptake capacity after the same treatment. The unprecedentedly high oxidative stability may represent an important breakthrough for the commercial implementation of these adsorbents.

\footnotetext{
${ }^{1}$ Department of Chemical and Biomolecular Engineering, Korea Advanced Institute of Science and Technology (KAIST), Daejeon 34141, Republic of Korea. Kyungmin Min and Woosung Choi contributed equally to this work. Correspondence and requests for materials should be addressed to

M.C. (email: mkchoi@kaist.ac.kr)
} 
C arbon capture and storage (CCS) has been investigated as an important option to reduce anthropogenic $\mathrm{CO}_{2}$ emissions ${ }^{1,2} \cdot \mathrm{CO}_{2}$ adsorption using aqueous amine solutions (e.g., monoethanolamine) is considered a benchmark technology for postcombustion $\mathrm{CO}_{2}$ capture ${ }^{3}$. However, despite the several decades of optimization, the technology still has inherent limitations including volatile amine loss, reactor corrosion, and the high energy consumption for regeneration ${ }^{1,4,5}$. To overcome these limitations, solid adsorbents that are noncorrosive and can lower the energy consumption have emerged as potential alternatives ${ }^{1,6-8}$. Among various adsorbents, amine-containing solids are considered to be the most promising adsorbents because of high $\mathrm{CO}_{2}$ adsorption selectivity in a typical flue gas containing dilute $\mathrm{CO}_{2}\left(<15 \% \mathrm{CO}_{2}\right)^{6-8}$. Such materials can be prepared by the heterogenization of amines in porous supports via the impregnation of polymeric amines such as poly(ethyleneimine) $(\mathrm{PEI})^{9-29}$, the grafting of aminosilanes ${ }^{14,20,23,24,29-39}$, or the polymerization of amine monomers within the support pores $^{14,20,39,40}$.

For commercial implementation of adsorbents, they should be stable upon repeated $\mathrm{CO}_{2}$ adsorption-desorption cycles over a long period. Generally, the low adsorbent stability necessitates the continuous addition of fresh adsorbents, which significantly increases the material cost for $\mathrm{CO}_{2}$ capture. Amine-containing adsorbents are known to degrade via various chemical pathways including the oxidative degradation of amines $15-22,30-33$, urea formation under the $\mathrm{CO}_{2}$-rich atmosphere ${ }^{21-25,33-35}$, steaminduced degradation of the porous supports ${ }^{20,26-28}$, and irreversible adsorption of $\mathrm{SO}_{2}{ }^{29,37,38}$. Aside from the oxidative degradation of amines, various solutions have been proposed for suppressing the degradation pathways. For instance, urea formation can be inhibited by selectively using secondary amines rather than primary amines 24,34 or injecting steam during adsorbent regeneration $14,22,23,28$. Steam-induced degradation can be solved by using porous supports with enhanced hydrothermal stability ${ }^{26-28}$. In addition, the amine poisoning by $\mathrm{SO}_{2}$ can be avoided by employing advanced desulfurization unit before $\mathrm{CO}_{2}$ capture $^{41}$. Therefore, the oxidative degradation of amines remains the biggest hurdle for the practical applications of these adsorbents.

The most ubiquitous impurity in flue gas is $\mathrm{O}_{2}(3-4 \%)^{1}$. Unfortunately, in the presence of $\mathrm{O}_{2}$, the amine-containing adsorbents undergo rapid deactivation because of amine oxidation $^{15-22,30-33}$. Amine oxidation is known to proceed via free radical formation by the reaction of $\mathrm{O}_{2}$ with amines at elevated temperatures ${ }^{42-44}$. The oxidation rate significantly depends on the amine structures. The isolated primary amines are known to be more stable than the isolated secondary amines ${ }^{30,31}$. In the case of PEI, the linear PEI mainly containing secondary amines is more stable than the branched PEI with a mixture of primary, secondary, and tertiary amines ${ }^{16}$. The results indicated that the co-existence of different types of amines can affect the oxidative degradation of amines. The polymers with only distant primary amines such as poly(allylamine) are more stable than conventional PEI ${ }^{17}$. Recently, the use of propylene spacers between amine groups has been found to substantially increase amine stability compared with the PEI containing ethylene spacers ${ }^{18}$. It has also been reported that the addition of poly(ethylene glycol) into polymeric amines can retard the amine oxidations due to hydrogen bonds between the hydroxy groups of poly(ethylene glycol) and the amines ${ }^{15}$. Despite these efforts, it still remains a great challenge to improve the oxidative stability of amines to a commercially meaningful level (i.e., stable over several months).

In the present work, we report the synthesis of a modified PEI/ silica that shows unprecedentedly high oxidative stability. The adsorbent was prepared by combining two strategies. First, PEI was functionalized with 1,2-epoxybutane (EB), which generates tethered 2-hydroxybutyl groups. Second, small amounts of chelators $(<2 \mathrm{wt} \%)$ were pre-supported into a silica support before the impregnation of functionalized PEI. We discovered that the polymeric amines contain p.p.m.-level metal impurities including $\mathrm{Fe}$ and $\mathrm{Cu}$, which catalyse amine oxidation. The addition of chelators as a catalyst poison could significantly suppress the rate of amine oxidation. Notably, the combination of two strategies resulted in great synergy, compared to when each method was used separately.

\section{Results}

PEI vs EB-functionalized PEI. The EB-functionalization of PEI (Nippon Shokubai, Epomin SP-012, MW 1200) was carried out as reported previously ${ }^{21}$ (Fig. 1). We reported that the functionalization can significantly increase the $\mathrm{CO}_{2}$ adsorption kinetics and amine stabilities against urea formation, while it can also retard the amine oxidation to some extent ${ }^{21}$. $50 \mathrm{wt} \%$ of PEI and EBfunctionalized PEI (EB-PEI) were supported onto a macroporous silica synthesized by spray-drying a water slurry containing a fumed silica ${ }^{21,26}$. The silica has a high $\mathrm{CO}_{2}$ accessibility to the supported amines and excellent steam stability arising from its large pore diameter ( $56 \mathrm{~nm}$ in average) and thick framework $(10-15 \mathrm{~nm})^{26}$. The $\mathrm{CO}_{2}$ adsorption-desorption behaviours of $\mathrm{PEI} / \mathrm{SiO}_{2}$ and $\mathrm{EB}-\mathrm{PEI} / \mathrm{SiO}_{2}$ were compared under practical temperature swing adsorption (TSA) conditions; $\mathrm{CO}_{2}$ adsorption was carried out with a simulated flue gas $\left(15 \% \mathrm{CO}_{2}, 10 \% \mathrm{H}_{2} \mathrm{O}, \mathrm{N}_{2}\right.$

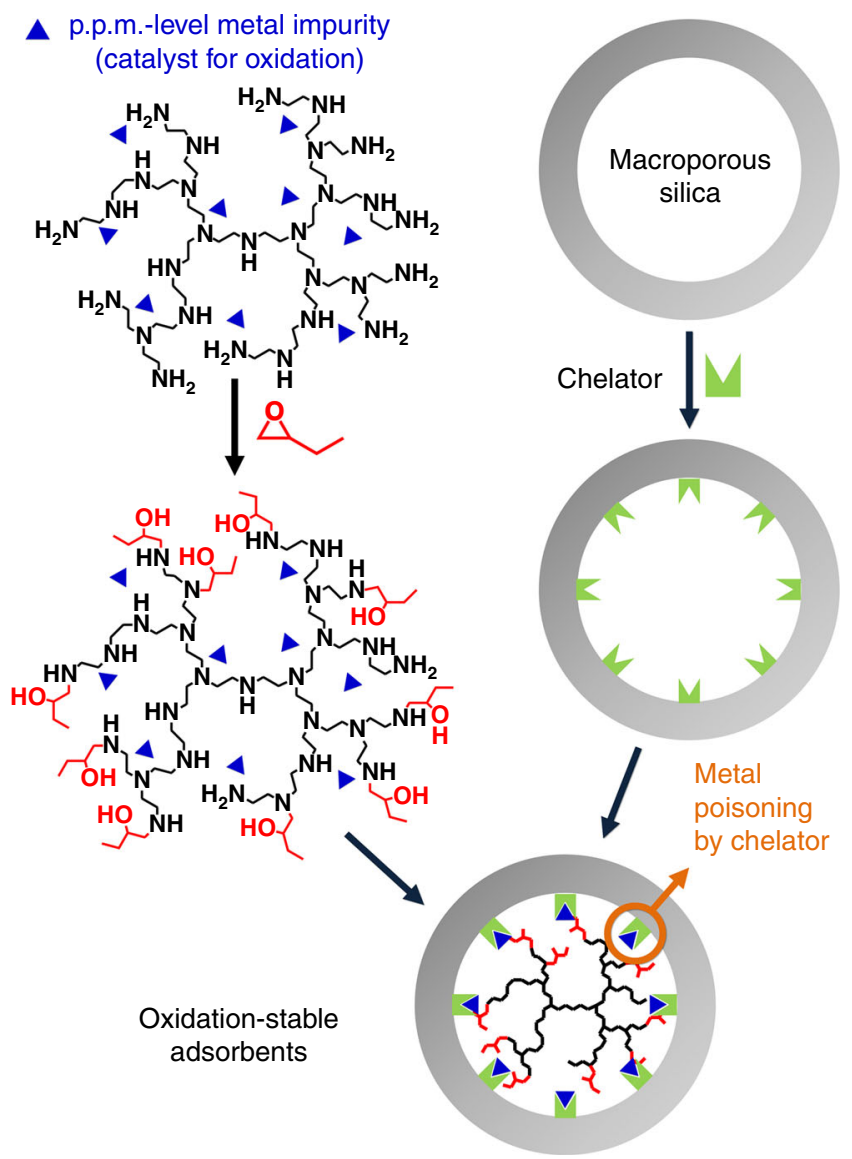

Fig. 1 Synthesis of oxidation-stable $\mathrm{CO}_{2}$ adsorbent. PEI was functionalized with 1,2-epoxybutane (EB), which generates tethered 2-hydroxybutyl groups. Small amounts of chelators were also pre-supported into a silica support to poison p.p.m.-level metal impurities in the polymeric amines that can catalyse the oxidative degradation of amines 

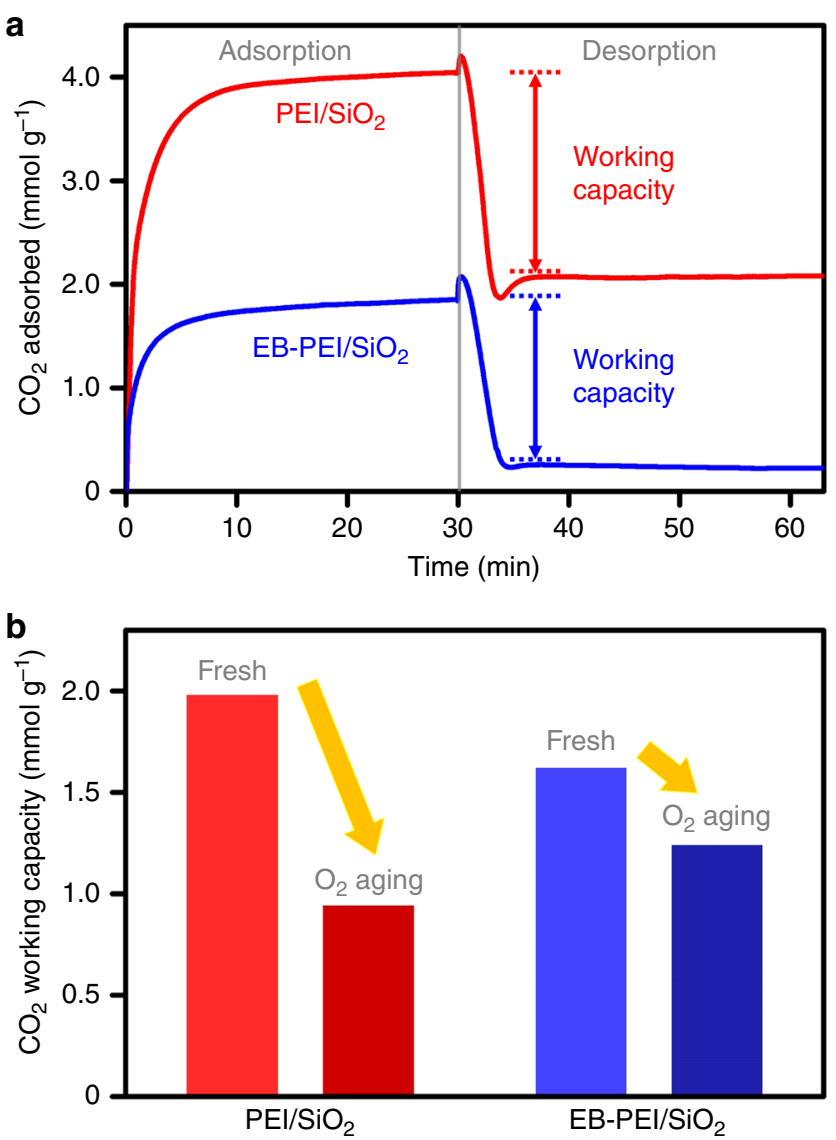

Fig. 2 Comparison of the $\mathrm{CO}_{2}$ adsorption-desorption behaviours and oxidative stabilities of $\mathrm{PEI} / \mathrm{SiO}_{2}$ and $\mathrm{EB}-\mathrm{PEI} / \mathrm{SiO}_{2} \cdot$ a $\mathrm{CO}_{2}$

adsorption-desorption profiles of the fresh adsorbents (adsorption: 15\% $\mathrm{CO}_{2}, 10 \% \mathrm{H}_{2} \mathrm{O}$, in $\mathrm{N}_{2}$ balance at $60^{\circ} \mathrm{C}$; desorption: $100 \% \mathrm{CO}_{2}$ at $110{ }^{\circ} \mathrm{C}$ ). b $\mathrm{CO}_{2}$ working capacities before and after the oxidative aging under $3 \% \mathrm{O}_{2}$ in $\mathrm{N}_{2}$ at $110^{\circ} \mathrm{C}$ for 1 day

balance) at $60{ }^{\circ} \mathrm{C}$ and desorption was carried out under $100 \%$ $\mathrm{CO}_{2}$ at $110^{\circ} \mathrm{C}$. As shown in Fig. 2a, EB-PEI/SiO ${ }_{2}\left(1.84 \mathrm{mmol} \mathrm{g}{ }^{-1}\right)$ showed smaller $\mathrm{CO}_{2}$ adsorption than $\mathrm{PEI} / \mathrm{SiO}_{2}\left(4.05 \mathrm{mmol} \mathrm{g}^{-1}\right)$ due to the reduced amine density after the EB-functionalization of $\mathrm{PEI}^{21}$. However, the amounts of desorbable $\mathrm{CO}_{2}$ during the adsorbent regeneration (i.e., $\mathrm{CO}_{2}$ working capacities) were similar for both samples (1.98 and $1.62 \mathrm{mmol} \mathrm{g}^{-1}$ for $\mathrm{PEI} / \mathrm{SiO}_{2}$ and $\mathrm{EB}$ $\mathrm{PEI} / \mathrm{SiO}_{2}$, respectively), because of inefficient $\mathrm{CO}_{2}$ desorption in $\mathrm{PEI} / \mathrm{SiO}_{2}$ at $110^{\circ} \mathrm{C}$. The more efficient regeneration of EB-PEI/ $\mathrm{SiO}_{2}$ can be attributed to the fact that EB-functionalization lowers the heat of $\mathrm{CO}_{2}$ adsorption by generating tethered 2hydroxybutyl groups on amines. The functional groups are electron-withdrawing groups that lower the amine basicity and also provide steric hindrance, lowering the heat of $\mathrm{CO}_{2}$ adsorption $^{21}$. According to differential scanning calorimetry, EB-PEI/ $\mathrm{SiO}_{2}$ exhibited a substantially lower heat of $\mathrm{CO}_{2}$ adsorption $(66.2$ $\left.\mathrm{kJ} \mathrm{mol}^{-1}\right)$ than $\mathrm{PEI} / \mathrm{SiO}_{2}\left(80.5 \mathrm{~kJ} \mathrm{~mol}^{-1}\right)$.

The $\mathrm{CO}_{2}$ working capacities of $\mathrm{PEI} / \mathrm{SiO}_{2}$ and $\mathrm{EB}-\mathrm{PEI} / \mathrm{SiO}_{2}$ before and after oxidative aging under $3 \% \mathrm{O}_{2}$ in $\mathrm{N}_{2}$ at $110{ }^{\circ} \mathrm{C}$ for $24 \mathrm{~h}$ are shown in Fig. 2b. The adsorbents were aged at the adsorbent regeneration temperature $\left(110^{\circ} \mathrm{C}\right)$, because it is the highest temperature the adsorbents can experience in TSA. PEI/ $\mathrm{SiO}_{2}$ showed a $52 \%$ decrease in $\mathrm{CO}_{2}$ working capacity after aging, whereas $\mathrm{EB}-\mathrm{PEI} / \mathrm{SiO}_{2}$ showed only a $23 \%$ decrease. These results show that the EB-functionalization of PEI can increase the oxidative stability of amines, which is consistent with our earlier results $^{21}$. The EB-functionalization converts the majority of the primary amines in PEI to secondary amines by alkylation with 2hydroxybutyl groups. ${ }^{13} \mathrm{C}$ NMR analysis showed that the primary: secondary:tertiary amine ratio in PEI is $36: 37: 27$, whereas EB-PEI has a 10:56:34 ratio $^{21}$. As Sayari pointed out, the oxidative degradation of amines in the PEI-type polymers is significantly affected by the co-existence of different types of amines ${ }^{16}$. Therefore, the increased stability of EB-PEI/SiO ${ }_{2}$ might originate from the increased portion of secondary amines at the expense of primary amines. Alternatively, it can also be attributed to the generation of abundant hydroxy $(-\mathrm{OH})$ groups after EBfunctionalization, which can form hydrogen bonds with nearby amines. Chuang et al. reported that oxidative stability of amines could be improved in the presence of additives containing hydroxy groups (e.g., polyethylene glycol) because of their abilities to form hydrogen bonds with amines ${ }^{15}$. FT-IR spectra (Supplementary Fig. 1) showed that N-H stretching bands (3360 and $3290 \mathrm{~cm}^{-1}$ ) became significantly broadened and the intensity of shoulder at $3160 \mathrm{~cm}^{-1}$ increased after the EB-functionalization of PEI, which could be attributed to the presence of amines hydrogen-bonded with hydroxy groups ${ }^{15}$.

Poisoning of metal impurities in amines. By coincidence, we discovered that the commercial PEI contains p.p.m.-level transition metal impurities, mainly $\mathrm{Fe}$ (17 p.p.m.) and $\mathrm{Cu}$ (6.9 p.p.m.) (Supplementary Table 1). Therefore, the EB-functionalized PEI had a more or less similar metal impurity content (Supplementary Table 1). Even though their concentrations are small, these metal species are known to catalyse amine oxidation by facilitating free radical formation via reaction with amines ${ }^{42-44}$. The $\mathrm{Fe}^{3+} / \mathrm{Fe}^{2+}$ and $\mathrm{Cu}^{2+} / \mathrm{Cu}^{+}$redox cycles can oxidize amines to form amine radicals via single electron transfer ${ }^{42-44}$, which can significantly increase the amine oxidation rate. The catalytic effects of these metal species on amine oxidation have been comprehensively investigated in the case of aqueous amine solutions, because Fe ions are continuously leached out by reactor corrosion and $\mathrm{Cu}$ ions are often deliberately added into the amine solutions to inhibit reactor corrosion ${ }^{42-44}$. However, in the case of solid adsorbents, possible contamination of commercial amine sources with these metal impurities and their catalytic effects on amine oxidation have been completely ignored.

To study the catalytic effects of the metal impurities on amine oxidation, we pre-supported six different types of chelators (Fig. 3a) as catalyst poisons onto a silica support. Then, the silicas were further impregnated with PEI and EB-PEI (Fig. 1). The ionic chelators were not soluble in the polymeric amines (PEI and EBPEI) and thus needed to be pre-dispersed on the silica surface to maximize their interaction with metal impurities. Because we introduced minor amounts of chelators ( $<2 \mathrm{wt} \%$ per composite), the $\mathrm{CO}_{2}$ working capacities of the adsorbents were not affected by the presence of the chelators (Supplementary Tables 2, 3). All chelators were effective in inhibiting amine oxidation (Fig. 3b, c). As the loading of chelators increased, more $\mathrm{CO}_{2}$ working capacities were retained after oxidative aging. Among the various chelators, phosphate or phosphonate sodium salts (1-3 in Fig. 3a) were the most effective at inhibiting amine oxidation in both PEI (Fig. 3b) and EB-PEI (Fig. 3c) systems. Notably, trisodiumphosphate (TSP, $\mathbf{1}$ in Fig. 3a), which is a completely inorganic and very economic chelator, showed the most promising inhibition effect. This is practically important because organic chelators themselves are known to be oxidatively degraded in the presence of oxygen and metal species ${ }^{45}$. This is why organic chelators are not generally regarded as good oxidation inhibitors in aqueous amine solutions ${ }^{44}$. Interestingly, TSP is known as a weak chelator that is ineffective in poisoning metal impurities in aqueous amine 

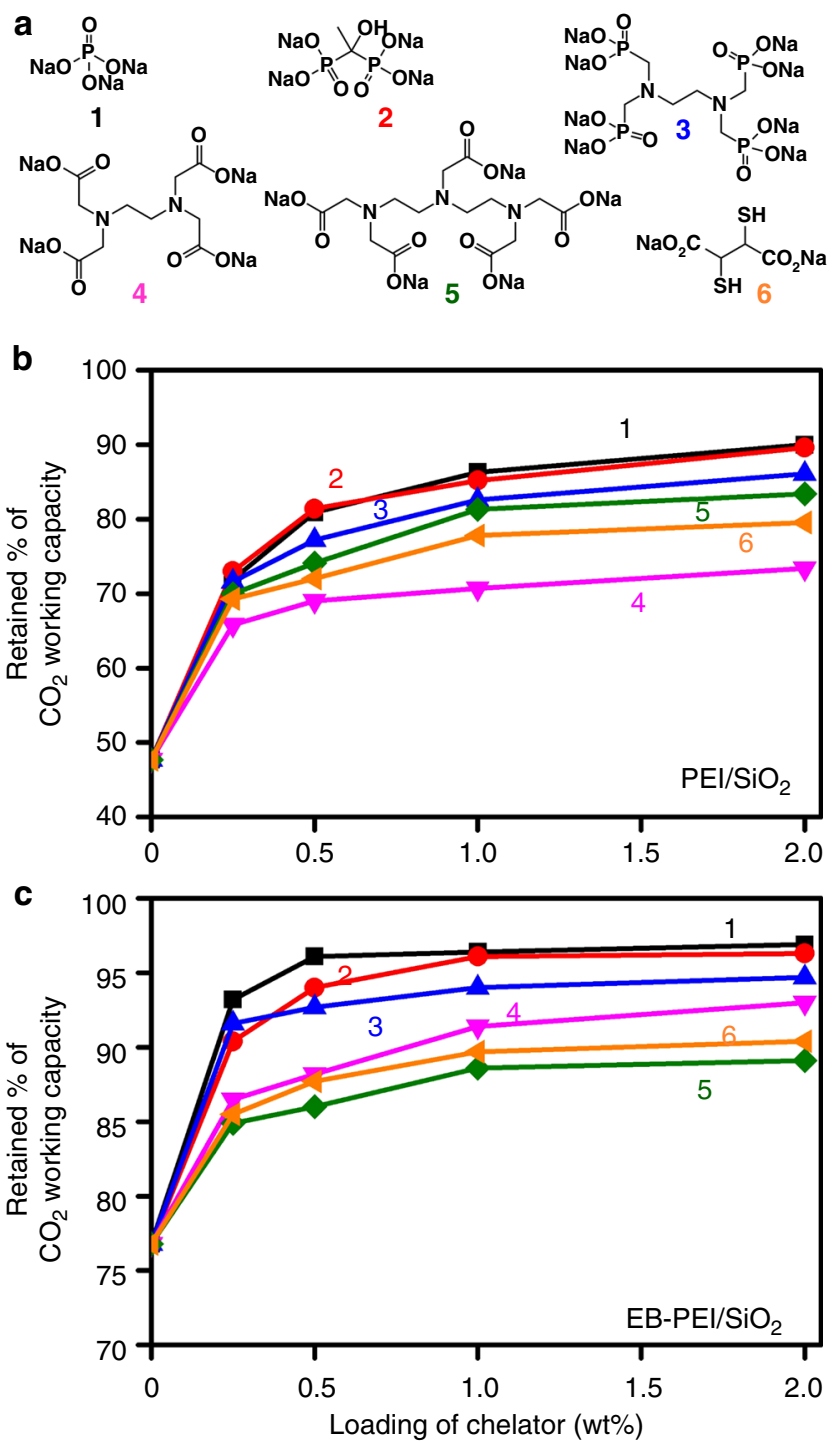

Fig. 3 Poisoning of metal impurities using chelators and its retardation effects on amine degradation. a Types of chelators. b, c Retained $\mathrm{CO}_{2}$ working capacity (\%) of $\mathrm{PEI} / \mathrm{SiO}_{2}$ (b) and $\mathrm{EB}-\mathrm{PEI} / \mathrm{SiO}_{2}$ (c) containing different amounts of chelators after oxidative aging under $3 \% \mathrm{O}_{2}$ in $\mathrm{N}_{2}$ at $110^{\circ} \mathrm{C}$ for 1 day. The numbers on plots indicate the types of chelators shown in a

solutions ${ }^{44}$. We believe that even the TSP could efficiently poison the metal impurities in the solid adsorbents, because of the larger formation constant of corresponding metal phosphates in less polar polymeric amines (i.e., PEI and EB-PEI) than water. It has been reported that the formation constants of various metal complexes increase with decreasing solvent polarity ${ }^{46}$.

Long-term oxidative stabilities of adsorbents. Because a real flue gas contains $\mathrm{CO}_{2}$ and $\mathrm{H}_{2} \mathrm{O}$ in addition to $\mathrm{O}_{2}$, the adsorbents must be stable under this atmosphere rather than under an $\mathrm{O}_{2} / \mathrm{N}_{2}$ mixed gas. Sayari thoughtfully pointed out that amine oxidation is slower in a real flue gas than in $\mathrm{O}_{2} / \mathrm{N}_{2}$ mixtures, because of the preferential interaction of amines with $\mathrm{CO}_{2}$ and $\mathrm{H}_{2} \mathrm{O}^{22}$. As shown in Fig. 4, we also confirmed that the addition of $\mathrm{CO}_{2}$ and/or $\mathrm{H}_{2} \mathrm{O}$ can substantially retard amine oxidation in both of $\mathrm{PEI} / \mathrm{SiO}_{2}$ and $\mathrm{EB}-\mathrm{PEI} / \mathrm{SiO}_{2}$ systems containing varied amounts of TSP. This means that the earlier aging experiments (Figs. 2 and 3) under 3\% $\mathrm{O}_{2}$ in $\mathrm{N}_{2}$ should be considered as accelerated aging because they
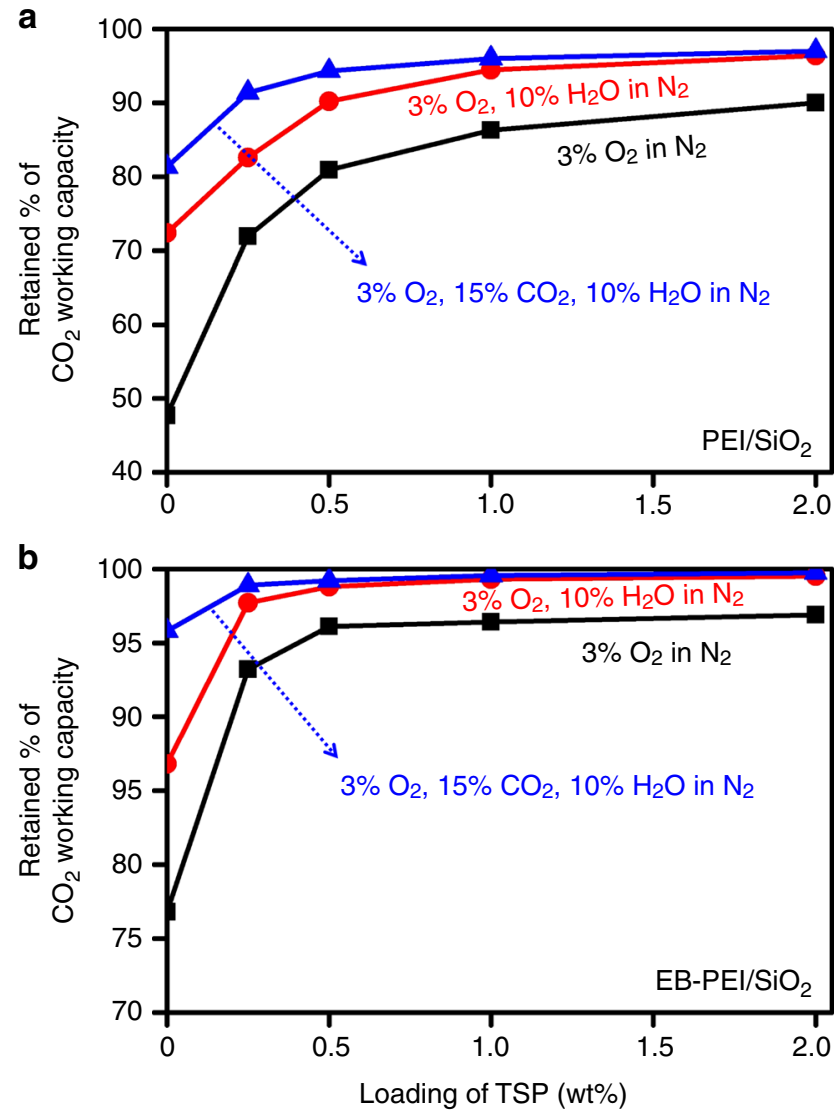

Fig. 4 Effects of gas compositions on the oxidative degradation of adsorbents. a, b Retained $\mathrm{CO}_{2}$ working capacity (\%) of $\mathrm{PEI} / \mathrm{SiO}_{2}$ (a) and $\mathrm{EB}-\mathrm{PEI} / \mathrm{SiO}_{2}$ (b) containing different contents of trisodiumphosphate (TSP), after oxidative aging under different gas compositions at $110^{\circ} \mathrm{C}$ for 1 day

were carried out in the absence of $\mathrm{CO}_{2}$ and $\mathrm{H}_{2} \mathrm{O}$. Therefore, to evaluate the long-term stability in a more realistic condition, we analysed the $\mathrm{CO}_{2}$ working capacities of adsorbents after aging in an $\mathrm{O}_{2}$-containing flue gas $\left(3 \% \mathrm{O}_{2}, 15 \% \mathrm{CO}_{2}, 10 \% \mathrm{H}_{2} \mathrm{O}\right.$ in $\mathrm{N}_{2}$ balance) for 30 days.

To separately understand the effects of EB-functionalization and TSP addition on long-term oxidative stabilities, four adsorbents, i.e., $\mathrm{PEI} / \mathrm{SiO}_{2}$ and $\mathrm{EB}-\mathrm{PEI} / \mathrm{SiO}_{2}$ prepared with and without 2 wt\% TSP, were investigated (Fig. 5a). Fitting with the first-order deactivation kinetics (trend lines in Fig. 5a) showed that each of the EB-functionalization of PEI (EB-PEI/SiO $\left.{ }_{2}\right)$ and the TSP addition into PEI ( $\left.\mathrm{PEI} / \mathrm{SiO}_{2}+2 \mathrm{wt} \% \mathrm{TSP}\right)$ could reduce the deactivation rate constant $\left(k_{\text {deac }}\right)$ approximately to half $\left(0.0546-0.0573 \mathrm{day}^{-1}\right)$, compared to that of $\mathrm{PEI} / \mathrm{SiO}_{2}(0.123$ day $\left.{ }^{-1}\right)$. Notably, the combination of both strategies (EB-PEI/SiO $\mathrm{S}_{2}+2$ wt $\%$ TSP) led to remarkable synergy, and the $k_{\text {deac }}(0.00258$ day ${ }^{-1}$ ) became $\sim 50$ times smaller than that of $\mathrm{PEI} / \mathrm{SiO}_{2}$. The adsorbent retained $91.5 \%$ of the initial $\mathrm{CO}_{2}$ working capacity after 30-days aging, while $\mathrm{PEI} / \mathrm{SiO}_{2}$ showed a complete loss of $\mathrm{CO}_{2}$ capacity. The great synergy between the EB-functionalization and TSP addition was attributed to the lower polarity of EB-PEI than that of PEI due to the presence of ethyl side groups (Fig. 1), which can increase the formation constants of metal phosphates (i.e., stronger poisoning of metal species). Our adsorption experiments showed that EB-PEI/SiO 2 adsorbed much less $\mathrm{H}_{2} \mathrm{O}$ (0.7 wt\%) than $\mathrm{PEI} / \mathrm{SiO}_{2}(4.7 \mathrm{wt} \%)$ under the simulated flue gas at $60^{\circ} \mathrm{C}$, which proved the lower polarity of EB-PEI.

In FT-IR spectra (Fig. 5b), $\mathrm{PEI} / \mathrm{SiO}_{2}$ without TSP showed a marked increase in $\mathrm{C}=\mathrm{O} / \mathrm{C}=\mathrm{N}$ stretching bands $\left(1670 \mathrm{~cm}^{-1}\right)$ 


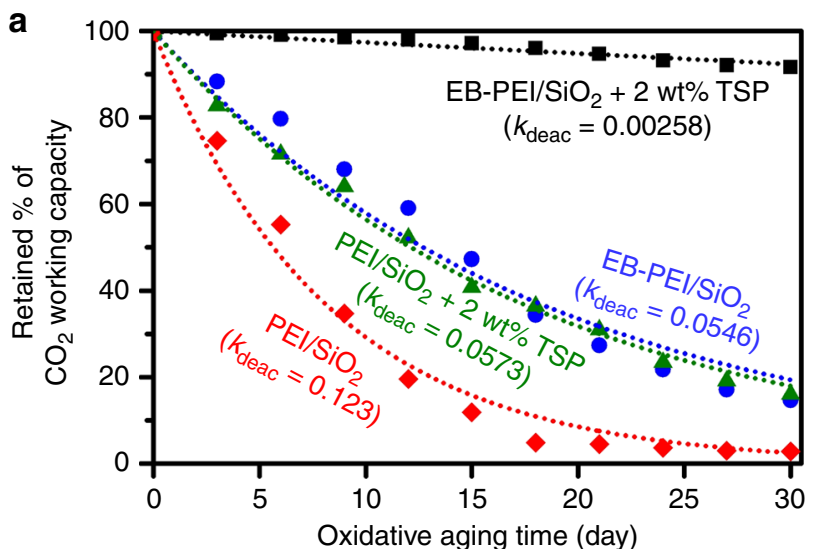

b

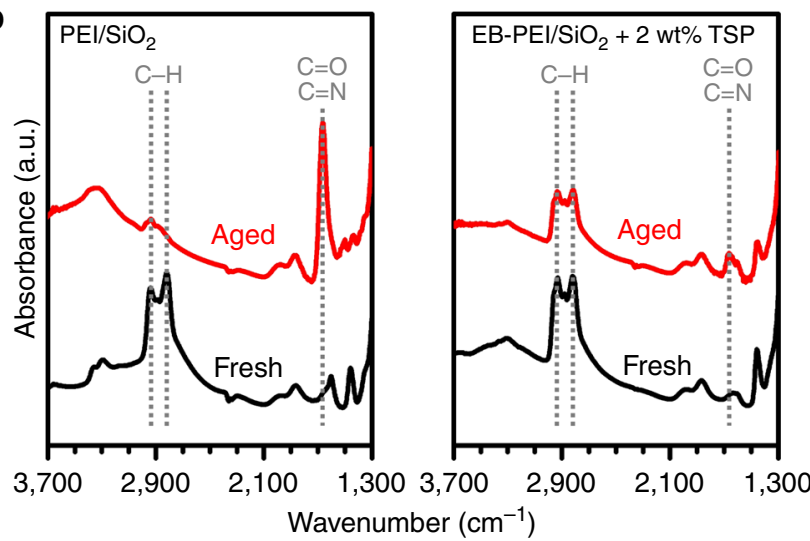

Fig. 5 Long-term oxidative stabilities of adsorbents. a Retained $\mathrm{CO}_{2}$ working capacity (\%) of $\mathrm{PEI} / \mathrm{SiO}_{2}$ and $\mathrm{EB}-\mathrm{PEI} / \mathrm{SiO}_{2}$ prepared with and without 2 wt $\%$ trisodiumphosphate (TSP) after aging under $3 \% \mathrm{O}_{2}, 15 \%$ $\mathrm{CO}_{2}, 10 \% \mathrm{H}_{2} \mathrm{O}$ in $\mathrm{N}_{2}$ balance at $110^{\circ} \mathrm{C}$. The trend lines are obtained by fitting with the first-order deactivation model. $\mathbf{b}$ FT-IR spectra of $\mathrm{PEI} / \mathrm{SiO}_{2}$ without TSP and $\mathrm{EB}-\mathrm{PEI} / \mathrm{SiO}_{2}$ with 2 wt $\% \mathrm{TSP}$, before and after 30 -days aging

and a decrease in $\mathrm{C}-\mathrm{H}$ stretching band $\left(2800-3000 \mathrm{~cm}^{-1}\right)$ after the 30 -days aging. The result indicates the formation of amide/ imine species $15,18,19,22$. We also found that $\mathrm{PEI} / \mathrm{SiO}_{2}$ lost $60 \%$ of the initial nitrogen content after the oxidative aging (Supplementary Fig. 2), which could be attributed to the hydrolysis of terminal imines to produce $\mathrm{NH}_{3}{ }^{42,43}$. Notably, carbon content also substantially decreased (32\%), which indicated a substantial polymer loss from the adsorbent. This implies that oxidation can partly cleave the polymer backbone into smaller fragments, which can be thermally evaporated. The chain degradation may be the consequence of complex amine oxidation reactions. It has been proposed that the ethylenediamine unit of PEI can be decomposed by oxidation into formamide and hemi-aminal ${ }^{47}$, which can subsequently be decomposed into formic acid, amines, and imines. Alternatively, the imines generated at the middle of the polymer backbone can be hydrolysed to produce amine and aldehydes, which can also result in chain cleavage. Based on these results, it can be concluded that the oxidation of polymeric amines can lead to the loss of $\mathrm{CO}_{2}$ capacity for two reasons: (1) the conversion of basic amines into non-basic amide/imine species, and (2) the accelerated loss of polymeric amines by oxidative fragmentation. In contrast, $\mathrm{EB}-\mathrm{PEI} / \mathrm{SiO}_{2}$ with $2 \mathrm{wt} \%$ TSP exhibited insubstantial change in FT-IR spectrum after aging. Furthermore, the decreases in nitrogen and carbon contents were insignificant $(<6.2 \%)$.

\section{Discussion}

We synthesized oxidation-stable amine-containing adsorbents via the functionalization of PEI with 1,2-epoxybutane (EB) and the poisoning of the p.p.m.-level metal impurities with chelators. The combination of two different strategies could make remarkable synergy, because chelators form metal complexes more efficiently (i.e., stronger poisoning) in less polar EB-functionalized PEI. We believe that the amine-containing solid adsorbent is beneficial in terms of oxidative stability compared to conventional aqueous amine solutions, because the aqueous amine solutions cause the continuous leaching of metal species by reactor corrosion and these metals act as catalysts for amine oxidation. This requires the continuous and stoichiometric addition of inhibitors such as oxygen/radical scavengers or chelators, and also the removal of their decomposition products ${ }^{44}$. In the case of solid adsorbents, the initial poisoning of the p.p.m.-level metal impurities in polymeric amines is sufficient to increase the oxidative stability over a long period because there is no continuous metal buildup from reactor corrosion. Furthermore, the polymeric amines less polar than water can also enable more efficient metal poisoning by chelators. The unprecedentedly high oxidative stability of amine-containing solid adsorbents may represent an important breakthrough toward their commercial implementation.

\section{Methods \\ Functionalization of PEI with 1,2-epoxybutane (EB). EB-functionalization of a commercial PEI (Nippon Shokubai, Epomin SP-012, MW 1200) was carried out as we reported previously ${ }^{21}$. In a typical synthesis, $12 \mathrm{~g}$ of 1,2-epoxybutane (Sigma- Aldrich, 99\%) was added dropwise to $60 \mathrm{~g}$ of a $33 \mathrm{wt} \%$ methanolic solution of PEI. The molar ratio between 1,2-epoxybutane and the nitrogen content in PEI (22 $\mathrm{mmol}_{\mathrm{N}} \mathrm{g}^{-1}$ ) was fixed at 0.37 . The reaction was carried out at room temperature for $12 \mathrm{~h}$ with stirring. The resultant methanolic solution containing $44 \mathrm{wt} \%$ EB-PEI was directly used for impregnation into a silica support.}

Preparation of a macroporous silica support. A highly macroporous silica support was prepared following the procedure we reported previously ${ }^{21,26}$. The silica was synthesized by spray-drying a water slurry containing $9.5 \mathrm{wt} \%$ fumed silica (OCI, KONASIL K-300) and $0.5 \mathrm{wt} \%$ silica sol (Aldrich, Ludox AS-30) as a binder. In a typical synthesis, $0.95 \mathrm{~kg}$ fumed silica, $0.05 \mathrm{~kg}$ silica sol, and $9 \mathrm{~kg}$ water were mixed and the resultant slurry was injected for spray-drying. The spraydrying was carried out using a spray dryer with a co-current drying configuration and a rotary atomizer (Zeustec ZSD-25). The injection rate was $30 \mathrm{~cm}^{3} \mathrm{~min}^{-1}$, and the rotating speed of the rotary atomizer was set to 4000 r.p.m. The air blowing inlet temperature was $210^{\circ} \mathrm{C}$ and the outlet temperature was $150^{\circ} \mathrm{C}$. The resultant silica particles were calcined in dry air at $600^{\circ} \mathrm{C}$ to sinter the fumed silica into a three-dimensional porous network.

Impregnation of chelators into the silica support. In the present work, chelators in a completely basic form (all acidic functional groups were titrated with $\mathrm{Na}^{+}$) were impregnated into the macroporous silica support using their aqueous solutions (typically, $0.25-2.0 \mathrm{wt} \%$ chelator concentrations). For the preparation of the aqueous solutions, trisodiumphosphate (1 in Fig. 3a, Sigma Aldrich, 96\%) and ethylenediaminetetraacetic acid tetrasodium salt dihydrate (4, Sigma Aldrich, 99\%) were directly dissolved in deionized water. In the cases of chelators in an acidic form, such as 1-hydroxyethane 1,1-diphosphonic acid monohydrate (2, Sigma Aldrich, 95\%), ethylenediamine tetramethylene phosphonic acid (3, Tokyo Chemical Industry, 98\%), diethylenetriaminepentaacetic acid (5, Sigma Aldrich, 99\%), and meso-2,3-dimercaptosuccinic acid (6, Sigma Aldrich, 98\%), controlled amounts of $\mathrm{NaOH}$ were dissolved together in deionized water to completely titrate acidic $\mathrm{H}^{+}$into $\mathrm{Na}^{+}$. After the wet impregnation of the chelators into the silica support, the samples were dried in a vacuum oven at $100{ }^{\circ} \mathrm{C}$ for $12 \mathrm{~h}$. The final loading of chelators was controlled in the range of $0-4 \mathrm{wt} \%$ with respect to the mass of silica support.

Preparation of the $\mathrm{PEI} / \mathrm{SiO}_{2}$ and EB-PEI/SiO ${ }_{2}$ adsorbents. Methanolic solutions of PEI and EB-PEI were impregnated into the macroporous silica supports preimpregnated with $0-4 \mathrm{wt} \%$ chelators. After impregnation, the samples were dried at $60{ }^{\circ} \mathrm{C}$ for $12 \mathrm{~h}$ in a vacuum oven to remove methanol completely. With respect to the mass of the final composite adsorbents, the polymer content was fixed to $50 \mathrm{wt}$ $\%$ and the chelator content was controlled in the range of $0-2 \mathrm{wt} \%$.

Material characterization. The heat of $\mathrm{CO}_{2}$ adsorption was measured by differential scanning calorimetry (Setaram Instrumentation, Setsys Evolution). Before 
the measurements, the samples were degassed at $100^{\circ} \mathrm{C}$ for $1 \mathrm{~h}$ under $\mathrm{N}_{2}$ flow $(50$ $\mathrm{cm}^{3} \mathrm{~min}^{-1}$ ). Then, the samples were cooled to $60^{\circ} \mathrm{C}$. Subsequently, the gas was switched to $15 \% \mathrm{CO}_{2}\left(50 \mathrm{~cm}^{3} \mathrm{~min}^{-1}\right)$. The heat of adsorption was calculated through the integration of the heat flow curve. Fourier transform infrared (FT-IR) spectra were recorded using an FT-IR spectrometer (Thermo Nicolet NEXUS 470). Prior to the analysis, $3 \mathrm{mg}$ of the adsorbents were grinded with $18 \mathrm{mg}$ of the silica (macroporous silica support) as a diluent. The mixtures were pressed into a selfsupporting wafer. Before the FT-IR measurements, each sample was degassed at $100^{\circ} \mathrm{C}$ for $3 \mathrm{~h}$ under vacuum in an in situ infrared cell equipped with $\mathrm{CaF}_{2}$ windows. FT-IR spectra were collected at room temperature. Elemental compositions $(\mathrm{C}, \mathrm{H}$, and $\mathrm{N}$ ) of the adsorbents were analysed using a FLASH 2000 (Thermo Scientific) instrument. The contents of transition metal impurities ( $\mathrm{Fe}, \mathrm{Cu}$, etc.) in PEI and EB-PEI were determined by inductively coupled plasma mass spectroscopy (ICP-MS) using an ICP-MS 7700S instrument (Agilent). In the case of EB-PEI, the metal concentrations were determined after the complete evaporation of the methanol solvent at $60^{\circ} \mathrm{C}$ for $12 \mathrm{~h}$ under vacuum after its synthesis.

$\mathrm{CO}_{2}$ adsorption-desorption experiments. $\mathrm{CO}_{2}$ adsorption-desorption profiles were collected by a thermogravimetric analysis-mass spectrometry (TGA-MS) setup $^{21,35}$. Prior to the measurements, all samples were degassed at $100^{\circ} \mathrm{C}$ for $1 \mathrm{~h}$ under $\mathrm{N}_{2}$ flow $\left(50 \mathrm{~cm}^{3} \mathrm{~min}^{-1}\right) . \mathrm{CO}_{2}$ adsorption was carried out using a simulated wet flue gas containing $15 \% \mathrm{CO}_{2}, 10 \% \mathrm{H}_{2} \mathrm{O}$, and $\mathrm{N}_{2}$ balance at $60^{\circ} \mathrm{C}$. After $30 \mathrm{~min}$ adsorption, the gas was switched to $100 \% \mathrm{CO}_{2}$ flow $\left(50 \mathrm{~cm}^{3} \mathrm{~min}^{-1}\right)$ and the temperature was increased to $110^{\circ} \mathrm{C}\left(\mathrm{ramp}: 20^{\circ} \mathrm{C} \mathrm{min}-1\right.$ ). Then the temperature was maintained for $30 \mathrm{~min}$ for the desorption process. The adsorbed amount of $\mathrm{CO}_{2}$ was calculated by subtracting the amount of adsorbed $\mathrm{H}_{2} \mathrm{O}$ (determined by mass spectrometry) from the total mass increase determined by TGA. To confirm the reliability of the TGA-MS results, the $\mathrm{CO}_{2}$ uptake was also cross-checked with an automated chemisorption analyser (Micromeritics, Autochem II 2920) specially equipped with a cold trap $\left(-10^{\circ} \mathrm{C}\right)$ for $\mathrm{H}_{2} \mathrm{O}$ removal in front of the TCD detector $^{21,35}$.

Data availability. The data that support the findings of this study are available from the corresponding author upon request.

Received: 2 November 2017 Accepted: 22 January 2018

Published online: 20 February 2018

\section{References}

1. D'Alessandro, D. M., Smit, B. \& Long, J. R. Carbon dioxide capture: prospects for new materials. Angew. Chem. Int. Ed. 49, 6058-6082 (2010).

2. Haszeldine, R. S. Carbon capture and storage: how green can black be? Science 325, 1647-1652 (2009)

3. Rochelle, G. T. Amine scrubbing for $\mathrm{CO}_{2}$ capture. Science 325, 1652-1654 (2009).

4. Figueroa, J. D., Fout, T., Plasynski, S., McIlvried, H. \& Srivastava, R. D. Advances in $\mathrm{CO}_{2}$ capture technology-the U.S. department of energy's carbon sequestration program. Int. J. Greenh. Gas. Control 2, 9-20 (2008).

5. Nguyen, T., Hilliard, M. \& Rochelle, G. T. Amine volatility in $\mathrm{CO}_{2}$ capture. Int. J. Greenh. Gas. Control 4, 707-715 (2010).

6. Wang, J. et al. Recent advances in solid sorbents for $\mathrm{CO}_{2}$ capture and new development trends. Energy Environ. Sci. 7, 3478-3518 (2014).

7. Choi, S., Drese, J. H. \& Jones, C. W. Adsorbent materials for carbon dioxide capture from large anthropogenic point sources. ChemSusChem 2, 796-854 (2009).

8. Bollini, P., Didas, S. A. \& Jones, C. W. Amine-oxide hybrid materials for acid gas separations. J. Mater. Chem. 21, 15100-15120 (2011).

9. Xu, X., Song, C., Andresen, J. M., Miller, B. G. \& Scaroni, A. W. Novel polyethylenimine-modified mesoporous molecular sieve of MCM-41 type as high-capacity adsorbent for $\mathrm{CO}_{2}$ capture. Energy Fuels. 16, 1463-1469 (2002).

10. Xu, X., Song, C., Andrésen, J. M., Miller, B. G. \& Scaroni, A. W. Preparation and characterization of novel $\mathrm{CO}_{2}$ "molecular basket" adsorbents based on polymer-modified mesoporous molecular sieve MCM-41. Microporous Mesoporous Mater. 62, 29-45 (2003).

11. Goeppert, A., Meth, S., Prakash, G. K. S. \& Olah, G. A. Nanostructured silica as a support for regenerable high-capacity organoamine-based $\mathrm{CO}_{2}$ sorbents. Energy Environ. Sci. 3, 1949-1960 (2010).

12. Ma, X., Wang, X. \& Song, C. "Molecular basket" sorbents for separation of $\mathrm{CO}_{2}$ and $\mathrm{H}_{2} \mathrm{~S}$ from various gas streams. J. Am. Chem. Soc. 131, 5777-5783 (2009).

13. Qi, G. et al. High efficiency nanocomposite sorbents for $\mathrm{CO}_{2}$ capture based on amine-functionalized mesoporous capsules. Energy Environ. Sci. 4, 444-452 (2011).

14. $\mathrm{Li}, \mathrm{W}$. et al. Steam-stripping for regeneration of supported amine-based $\mathrm{CO}_{2}$ adsorbents. ChemSusChem 3, 899-903 (2010).
15. Srikanth, C. S. \& Chuang, S. S. C. Spectroscopic investigation into oxidative degradation of silica-supported amine sorbents for $\mathrm{CO}_{2}$ capture. ChemSusChem 5, 1435-1442 (2012).

16. Ahmadalinezhad, A. \& Sayari, A. Oxidative degradation of silica-supported polyethylenimine for $\mathrm{CO}_{2}$ adsorption: insights into the nature of deactivated species. Phys. Chem. Chem. Phys. 16, 1529-1535 (2014).

17. Bali, S., Chen, T. T., Chaikittisilp, W. \& Jones, C. W. Oxidative stability of amino polymer-alumina hybrid adsorbents for carbon dioxide capture. Energy Fuels. 27, 1547-1554 (2013).

18. Pang, S. H., Lee, L. C., Sakwa-Novak, M. A., Lively, R. P. \& Jones, C. W. Design of amino polymer structure to enhance performance and stability of $\mathrm{CO}_{2}$ sorbents: poly(propylenimine) vs poly(ethylenimine). J. Am. Chem. Soc. 139, 3627-3630 (2017).

19. Srikanth, C. S. \& Chuang, S. S. C. Infrared study of strongly and weakly adsorbed $\mathrm{CO}_{2}$ on fresh and oxidatively degraded amine sorbents. J. Phys. Chem. C. 117, 9196-9205 (2013).

20. $\mathrm{Li}, \mathrm{W}$. et al. Structural changes of silica mesocellular foam supported aminefunctionalized $\mathrm{CO}_{2}$ adsorbents upon exposure to steam. ACS Appl. Mater. Interfaces 2, 3363-3372 (2010).

21. Choi, W. et al. Epoxide-functionalization of polyethyleneimine for synthesis of stable carbon dioxide adsorbent in temperature swing adsorption. Nat. Commun. 7, 12640 (2016)

22. Heydari-Gorii, A. \& Sayari, A. Thermal, oxidative, and $\mathrm{CO}_{2}$-induced degradation of supported polyethylenimine adsorbents. Ind. Eng. Chem. Res. 51, 6887-6894 (2012).

23. Sayari, A. \& Belmabkhout, Y. Stabilization of amine-containing $\mathrm{CO}_{2}$ adsorbents: dramatic effect of water vapor. J. Am. Chem. Soc. 132, 6312-6314 (2010).

24. Sayari, A., Heydari-Gorji, A. \& Yang, Y. $\mathrm{CO}_{2}$-induced degradation of aminecontaining adsorbents: reaction products and pathways. J. Am. Chem. Soc. 134, 13834-13842 (2012)

25. Drage, T. C., Arenillas, A., Smith, K. M. \& Snape, C. E. Thermal stability of polyethylenimine based carbon dioxide adsorbents and its influence on selection of regeneration strategies. Microporous Mesoporous Mater. 116 504-512 (2008).

26. Min, K., Choi, W. \& Choi, M. Macroporous silica with thick framework for steam-stable and high-performance poly(ethyleneimine)/silica $\mathrm{CO}_{2}$ adsorbent. ChemSusChem 10, 2518-2526 (2017).

27. Chaikittisilp, W., Kim, H. J. \& Jones, C. W. Mesoporous alumina-supported amines as potential steam-stable adsorbents for capturing $\mathrm{CO}_{2}$ from simulated flue gas and ambient air. Energy Fuels. 25, 5528-5537 (2011).

28. Hammache, S. et al. Comprehensive study of the impact of steam on polyethyleneimine on silica for $\mathrm{CO}_{2}$ capture. Energy Fuels. 27, 6899-6905 (2013).

29. Rezaei, F. \& Jones, C. W. Stability of supported amine adsorbents to $\mathrm{SO}_{2}$ and $\mathrm{NO}_{\mathrm{x}}$ in postcombustion $\mathrm{CO}_{2}$ capture. 1. Single-component adsorption. Ind. Eng. Chem. Res. 52, 12192-12201 (2013).

30. Bollini, P., Choi, S., Drese, J. H. \& Jones, C. W. Oxidative degradation of aminosilica adsorbents relevant to postcombustion $\mathrm{CO}_{2}$ capture. Energy Fuels. 25, 2416-2425 (2011).

31. Heydari-Gorji, A., Belmabkhout, Y. \& Sayari, A. Degradation of aminesupported $\mathrm{CO}_{2}$ adsorbents in the presence of oxygen-containing gases. Microporous Mesoporous Mater. 145, 146-149 (2011).

32. Ahmadalinezhad, A., Tailor, R. \& Sayari, A. Molecular-level insights into the oxidative degradation of grafted amines. Chem. Eur. J. 19, 10543-10550 (2013).

33. Didas, S. A., Zhu, R., Brunelli, N. A., Sholl, D. S. \& Jones, C. W. Thermal, oxidative and $\mathrm{CO}_{2}$ induced degradation of primary amines used for $\mathrm{CO}_{2}$ capture: effect of alkyl linker on stability. J. Phys. Chem. C. 118, 12302-12311 (2014).

34. Sayari, A., Belmabkhout, Y. \& Da'na, E. $\mathrm{CO}_{2}$ deactivation of supported amines: does the nature of amine matter? Langmuir 28, 4241-4247 (2012).

35. Kim, C., Cho, H. S., Chang, S., Cho, S. J. \& Choi, M. An ethylenediaminegrafted Y zeolite: a highly regenerable carbon dioxide adsorbent via temperature swing adsorption without urea formation. Energy Environ. Sci. 9, 1803-1811 (2016).

36. McDonald, T. M. et al. Cooperative insertion of $\mathrm{CO}_{2}$ in diamine-appended metal-organic frameworks. Nature 519, 303-308 (2015).

37. Khatri, R. A., Chuang, S. S. C., Soong, Y. \& Gray, M. Thermal and chemical stability of regenerable solid amine sorbent for $\mathrm{CO}_{2}$ capture. Energy Fuels. 20, 1514-1520 (2006).

38. Belmabkhout, Y. \& Sayari, A. Isothermal versus non-isothermal adsorption-desorption cycling of triamine-grafted pore-expanded MCM-41 mesoporous silica for $\mathrm{CO}_{2}$ capture from flue gas. Energy Fuels. 24, 5273-5280 (2010).

39. Qi, G., Fu, L. \& Giannelis, E. P. Sponges with covalently tethered amines for high-efficiency carbon capture. Nat. Commun. 5, 5796 (2014).

40. Hicks, J. C. et al. Designing adsorbents for $\mathrm{CO}_{2}$ capture from flue gashyperbranched aminosilicas capable of capturing $\mathrm{CO}_{2}$ reversibly. J. Am. Chem. Soc. 130, 2902-2903 (2008). 
41. Rao, A. B. \& Rubin, E. S. A technical, economic, and environmental assessment of amine-based $\mathrm{CO}_{2}$ capture technology for power plant greenhouse gas control. Environ. Sci. Technol. 36, 4467-4475 (2002).

42. Chi, S. \& Rochelle, G. Oxidative degradation of monoethanolamine. Ind. Eng. Chem. Res. 41, 4178-4186 (2002).

43. Goff, G. S. \& Rochelle, G. T. Monoethanolamine degradation: $\mathrm{O}_{2}$ mass transfer effects under $\mathrm{CO}_{2}$ capture conditions. Ind. Eng. Chem. Res. 43 6400-6408 (2004).

44. Goff, G. S. \& Rochelle, G. T. Oxidation inhibitors for copper and iron catalyzed degradation of monoethanolamine in $\mathrm{CO}_{2}$ capture processes. Ind. Eng. Chem. Res. 45, 2513-2521 (2006).

45. Seibig, S. \& van Eldik, R. Kinetics of $\left[\mathrm{Fe}^{\mathrm{II}}(\right.$ edta) $]$ oxidation by molecular oxygen revisited. New evidence for a multistep mechanism. Inorg. Chem. 36, 4115-4120 (1997).

46. Mui, K.-K., Mcbryde, W. A. E. \& Nieboer, E. The stability of some metal complexes in mixed solvents. Can. J. Chem. 52, 1821-1833 (1974).

47. Idris, S. A., Mkhatresh, O. A. \& Heatley, F. Assignment of ${ }^{1} \mathrm{H}$ NMR spectrum and investigation of oxidative degradation of poly(ethylenimine) using ${ }^{1} \mathrm{H}$ and ${ }^{13}$ C 1-D and 2-D NMR. Polym. Int. 55, 1040-1048 (2006).

\section{Acknowledgements}

This work was supported by Korea CCS R\&D Center (KCRC) grant funded by the Korea government (Ministry of Science, ICT \& Future Planning) (NRF-2014M1A8A1049256) and the Basic Science Research Program through the National Research Foundation of Korea (NRF-2017R1A2B2002346).

\section{Author contributions}

M.C. conceived and designed this study. K.M., W.C., and C.K. performed material synthesis, characterizations, and $\mathrm{CO}_{2}$ adsorption-desorption experiments. M.C. wrote the manuscript with assistance from K.M., W.C., and C.K. All authors discussed the results and commented on the manuscript.

\section{Additional information}

Supplementary Information accompanies this paper at https://doi.org/10.1038/s41467018-03123-0.

Competing interests: The authors declare no competing financial interests.

Reprints and permission information is available online at http://npg.nature.com/ reprintsandpermissions/

Publisher's note: Springer Nature remains neutral with regard to jurisdictional claims in published maps and institutional affiliations.

(c) (i) Open Access This article is licensed under a Creative Commons Attribution 4.0 International License, which permits use, sharing, adaptation, distribution and reproduction in any medium or format, as long as you give appropriate credit to the original author(s) and the source, provide a link to the Creative Commons license, and indicate if changes were made. The images or other third party material in this article are included in the article's Creative Commons license, unless indicated otherwise in a credit line to the material. If material is not included in the article's Creative Commons license and your intended use is not permitted by statutory regulation or exceeds the permitted use, you will need to obtain permission directly from the copyright holder. To view a copy of this license, visit http://creativecommons.org/ licenses/by/4.0/.

(C) The Author(s) 2018 